\title{
A Study of Enteric Bacterial and Parasitic Pathogens among the Food Handlers of Gauhati Medical College and Hospital
}

\author{
Rana Doley*, Arunjyoti Sarmah and Dipa Barkataki
}

Vill. Karpunpuli, P.O. Jorhat Engg. College, P.S Jorhat, Dist. Jorhat, State - Assam, Pin. 785007, India

*Corresponding author

\section{Keywords \\ Foodhandler, Hand hygiene, Intestinal parasite, Formol ether method, Ascarias lumbricoides}

Article Info

Accepted:

24 June 2018

Available Online:

10 July 2018

\section{A B S T R A C T}

Food borne diseases pose an important public health problem in developed and developing countries. The spread of food borne diseases via food handlers is a common and persistent problem worldwide. In developed countries, up to $30 \%$ of the population suffers from food borne diseases each year, whereas in developing countries up to 2 million deaths are estimated per year (WHO, Geneva 2007). Objectives of the study are to know the prevalence intestinal parasites and rate of hand washing practices among the food handlers. This study was conducted in all food handlers of Gauhati Medical College and Hospital for a period of one year from June 2013 to May 2014. Stool samples were collected and processed for detection of parasites by macroscopic, direct microscopy, microscopy after formol - ether concentration methods and for enteric pathogens samples were processed in MacConkey agar, DCA, XLD agar, Selenite F broth and identified by standard methods as per CLSI guideline. Total 116 food handlers were studied, out of which $18(15.52 \%)$ cases were found positive for parasites only while no cases were found positive for enteric bacterial pathogens. Protozoa were the most common isolates [10 (8.62\%)] of which Entamoeba histolytica [7 (38.88\%)] accounted for highest percentage of cases followed by Giardia [3(16.67\%)]. Among the Helminths [8 (6.03\%)], Ascaris lumbricoides [4 (22.2\%)] was the most common finding followed by hookworm [3(16.67\%)] and Trichuris trichura [1 (5.56\%)]. Hand washing practice after toilet with soap and water was found to be $100 \%$. Hand washing practice after touching dirty materials or different body parts was found to be $75 \%$. From our study as we found that the food handlers might be a source of transmission of pathogens to consumers, so we should give stress on maintaining good personal hygiene specially hand hygiene and hygienic food handling practices for preventing of transmission of pathogens from food handlers to consumers. Hence, we can conclude that the screening of food handlers and training for hand hygiene practices has to be imposed in every health care set up regularly.

\section{Introduction}

Food borne diseases are a public health problem in developed and developing countries. The spread of food borne diseases via food handlers is a common and persistent problem worldwide. The World health organization (WHO) estimated that in 
developed countries, up to $30 \%$ of the population suffer from food borne diseases each year, whereas in developing countries up to 2 million deaths are estimated per year (WHO, Geneva 2007).

Food handler is any person who handles food, regardless whether he or she actually prepares or serves it. They are the most important sources for the transfer of microorganisms to the food from their skin, nose, and bowel and also from the contaminated food prepared and served by them (Mohan V et al.,). Food handlers with poor personal hygiene could be potential source of infections of many intestinal helminthes, protozoa and enteropathogenic bacteria. Transmission of intestinal parasites and entero-pathogenic bacteria occurs directly or indirectly through food, water, nails, and fingers etc. indicating the importance of fecal-oral human-to-human transmission (Saeed et al., Andargie et al., Mohan et al., ).

Good hygiene, both personal and in food handling practices, is the basis for preventing the transmission of pathogens from food handling personnel to consumer ((Murat et $a l$. ,). An estimated 76 million food borne illnesses occur annually in the United States. These food-borne illnesses resulting an estimated 3,25,000 hospitalizations and 5000 deaths every year in the United States. The cost of the most common food borne illnesses in the United States is estimated at \$6.5-\$34.9 billion annually (Mead PS et al., 1999). In the past few decades, the epidemiology of food borne diseases has changed with several emerging and reemerging pathogens. Some of them may pose a low risk to most individuals, but may be life-threatening to others (Zain MM et al., 2002).

Intestinal parasites and protozoal infections are among the most common infections worldwide. It is estimated that some 3.5 billion people are affected, and that 450 million are ill as a result of these infections, the majority being children (WHO, Geneva 1998).

The prevalence of the intestinal parasitic infections varies from one region to another and it also depends largely on the diagnostic methods which are employed and the number of stool examinations which are done. In India, malnutrition, unhygienic conditions, improper disposal of sewage and the nonavailability of potable water supplies in the rural and the urban areas are responsible for the high rate of intestinal parasitic infections (Mayta $\mathrm{H}$ et al.,). The Centre for Disease Control and Prevention (CDC) have stated that poor personal hygiene is the third most commonly reported food preparation practice contributing to food-borne diseases (Lillquist DR et al.,). Parasitic infections in food handlers may pose a real threat to those who are more susceptible to infection like hospitalized patients especially those who suffered from immune deficient conditions (Robinson et al.,). Persons with asymptomatic infections and carriers pose a greater danger to the public because the worker keeps on working unmindful of the infection he is transmitting.

The main and objectives of this study for considering the role of food handlers in transmitting food borne disease, the present study has been taken with the following aims and objectives:

To see the presence of intestinal parasite among the food handlers

To know the prevalence of entero-pathogenic bacteria among the food handlers working in various food establishments of Gauhati Medical College \& Hospital.

To know the rate of hand washing practices among the food handlers 


\section{Materials and Methods}

A Hospital based cross sectional study was conducted among all food handlers working in various kitchens in the premises of Gauhati Medical College and hospital, Guwahati, for a period of one year from June 2013 to May 2014.

\section{Place of study}

The study was carried out in the department of Microbiology, Gauhati medical college and hospital (GMCH), Guwahati.

\section{Ethical clearance}

The study proposed with relevant documents was submitted to the Institutional Ethics Committee (IEC), GMCH for review and approval. The study commenced with the ethical approval and clearance certificate was obtained from the IEC, GMCH.

\section{Sample size}

A total of 116 food handlers were enrolled and studied for the presence of enteric bacterial and parasitic pathogens. Information on age, sex, education level, hand washing practice etc. of each food handlers was collected in a preformed questionnaire (Zain et al., Khurana et al.,).

\section{Inclusion criteria}

Food handlers who did not take treatment for any intestinal ailment prior to 3 months were included in the study.

\section{Exclusion criteria}

Those food handlers who could not be contacted during the study period were excluded from the study.

\section{Sample collection}

A sterile wide bore container and plastic spoon was given to the participants for collection of fresh stool samples. The participants were advised to collect a spoonful of stool specimen that has been passed into a clean bedpan or on a piece of toilet tissue or old newspaper and to transfer it to the container with the spoon provided and close the lid. It was strictly instructed to avoid mixing the specimen with dirt, water or urine (Mackie and McCartney).

The container with the specimen was labeled with the participants' name, serial number and the time of passing of stool. Participants were advised not to take barium sulphate, bismuth, mineral oil, anti-diarrhoeal agents and some antibiotics such as tetracycline during the 10 days before the collection of stool specimens.

For protozoa and helminths, at least 2 stool samples were collected since many parasites do not appear in faecal specimens consistently on daily basis.

The stool samples were processed and examined within 2 hours of collection to limit contamination and bacterial overgrowth. For isolation of enteric pathogenic bacteria (Salmonella, Shigella), the specimen should be examined and cultured as soon as it is delivered to the laboratory. If this is not possible, the specimen should be stored at $4 \mathrm{C}$ (Parija SC).

Sample processing: (WHO, Geneva 2003)

Each stools specimen was examined for parasites by the following techniques

1. Macroscopic examination for consistency, colour, odour, $\mathrm{pH}$ and parasitic elements.

2. Direct Microscopic examination by: 
a) Saline wet mount.

b) Iodine wet mount.

c) Modified acid fast staining.

3. Microscopic Examination after Formolether concentration.

\section{For isolation of enteric pathogens} (Salmonella and Shigella)

The stool sample were first cultured on plates of one or more kinds of selective media, both directly and after preliminary culture in a liquid enrichment medium, the plates were observed for the presence of Salmonella or Shigella like colonies.

\section{Culture media used}

MacConkey Agar (Mackie and MacCartney pg.108)

Deoxycholate Citrate Agar (Agar Medium J)

Xylose Lysine Deoxycholate Agar (XLD Agar)

Selenite F broth (Mackie and MacCartney)

A well separated colony was picked to obtain a pure culture and the pure culture was identified first by a selection of biochemical tests and finally by agglutination tests with specific antisera from Denka and Seiken, Japan.

\section{Classification of socioeconomic status}

The participants taken up for study were divided into 5 socioeconomic groups as per Kuppuswamy classification based on their educational qualifications, profession and monthly income.

(Park's textbook of preventive and social medicine $22^{\text {nd }}$ edition).

\section{Results and Discussion}

Of the 116 cases enrolled in our study, 105 were male and 11 were female (male:female=9.55:1). The majority of cases belong to 20-29 year age group (51.72\%) followed by 30-39 year age group (20.69\%) [Table 1]. $67(57.76 \%)$ of the cases belong to Upper Lower (UL) class of socio-economic strata as per Kuppuswamy socio-economic scale followed by Lower Middle (LM) [41 (35.34\%)] and Upper Middle (UM) [8 $(6.90 \%)]$. [Table 2]

Of the total cases, $18(15.52 \%)$ cases were found to be positive for enteric pathogens. Of these 18 cases, all were parasitic pathogens and no enteric bacterial pathogen was isolated. Moreover, of these 18 cases, the most common etiologic agent was observed to be Entamobea histolytica [7 (38.88\%)] followed by Ascarias lumbricoides [4 (22.22\%)], Giardia spp [3 (16.67\%)], Hookworm [3 (16.67\%)] and Trichuris trichiura [1 (5.56\%)] [Figure 1]. Of the positive cases, the commonest age group involved was the 20-29 year age group [9 (50\%)] followed by the 40 49 year age group [5 (27.78\%)] [Table 3]. 14 $(77.78 \%)$ of the positive cases belonged to the UL socio-economic strata while $4(22.22 \%)$ belonged to the LM socio-economic strata [Figure 2].

We also studied the hand hygiene practices of the food handlers enrolled in our study and it was observed that all the 116 cases washed their hands with soap and water after using toilet but $29(25 \%)$ cases did not comply with hand washing practices after touching dirty materials or different body parts. Moreover, of the positive cases (18), there was $100 \%$ compliance with hand hygiene after toilet usage but $3(16.67 \%)$ cases were found to be non-compliant with hand hygiene after touching dirty materials or different body parts [Table 4]. 
Table 1: Showing age and sex distribution of food handlers

\begin{tabular}{|l|l|l|l|}
\hline \multirow{2}{*}{$\begin{array}{l}\text { Age group in } \\
\text { years }\end{array}$} & \multicolumn{2}{|c|}{ Sex } & $\begin{array}{l}\text { Total } \\
\text { No. / } \%)\end{array}$ \\
\cline { 2 - 4 } & $\begin{array}{l}\text { Male } \\
\text { No. / (\%) }\end{array}$ & $\begin{array}{l}\text { Female } \\
\text { No. / } \%)\end{array}$ & \\
\hline $10-19$ & $7(6.03 \%)$ & Nil & $7(6.03 \%)$ \\
\hline $20-29$ & $59(50.86 \%)$ & $1(0.86 \%)$ & $60(51.72 \%)$ \\
\hline $30-39$ & $17(14.66 \%)$ & $7(6.03 \%)$ & $24(20.69 \%)$ \\
\hline $40-49$ & $20(17.24 \%)$ & $3(2.59 \%)$ & $23(19.83 \%)$ \\
\hline $50-59$ & $2(1.72 \%)$ & Nil & $2(1.72 \%)$ \\
\hline Total & $105(90.51 \%)$ & $11(9.48 \%)$ & $116(100 \%)$ \\
\hline
\end{tabular}

Table 2: Showing distribution of socio-economic status of the food handlers

\begin{tabular}{|l|l|l|}
\hline Class & No & $\%$ \\
\hline UM & 8 & $6.90 \%$ \\
\hline LM & 41 & $35.34 \%$ \\
\hline UL & 67 & $57.76 \%$ \\
\hline Total & & $100 \%$ \\
& 116 & \\
\hline
\end{tabular}


Table 3: Age distribution of all positive cases

\begin{tabular}{|l|l|l|}
\hline Age & No of positive samples & Percentage \\
\hline $20-29$ & 9 & $50 \%$ \\
\hline $30-39$ & 3 & $16.67 \%$ \\
\hline $40-49$ & 5 & $27.78 \%$ \\
\hline $50-59$ & 1 & $5.56 \%$ \\
\hline Total & 18 & $100 \%$ \\
\hline
\end{tabular}

Table.4 Hand washing practices among the food handlers of positive samples

\begin{tabular}{|l|l|l|}
\hline Hand washing practice with soap and water & Yes (\%) & No (\%) \\
\hline After toilet & $18(100 \%)$ & $0(0 \%)$ \\
\hline After touching dirty materials or different body & 15 & $3(16.67 \%)$ \\
parts & $(83.33 \%)$ & \\
\hline
\end{tabular}


Figure.1 Etiological distribution of positive cases

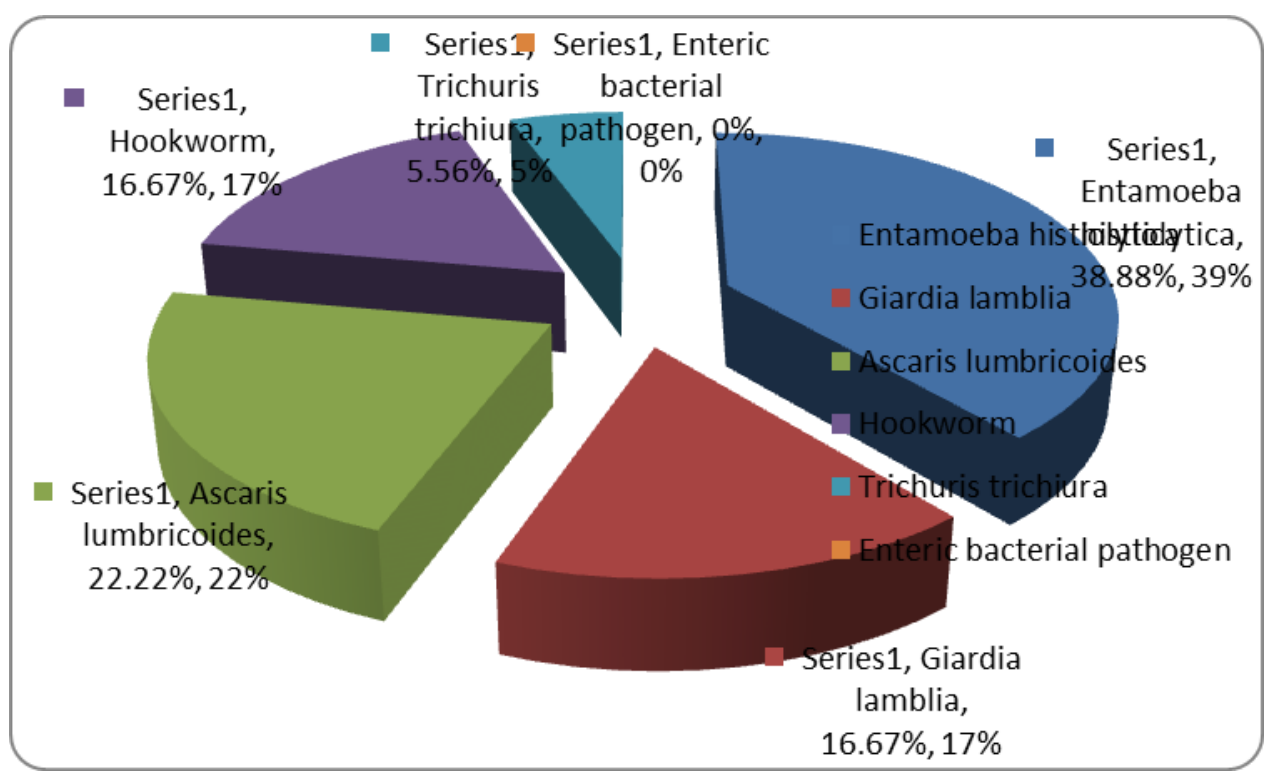

Figure.2 Socio economic status of positive cases

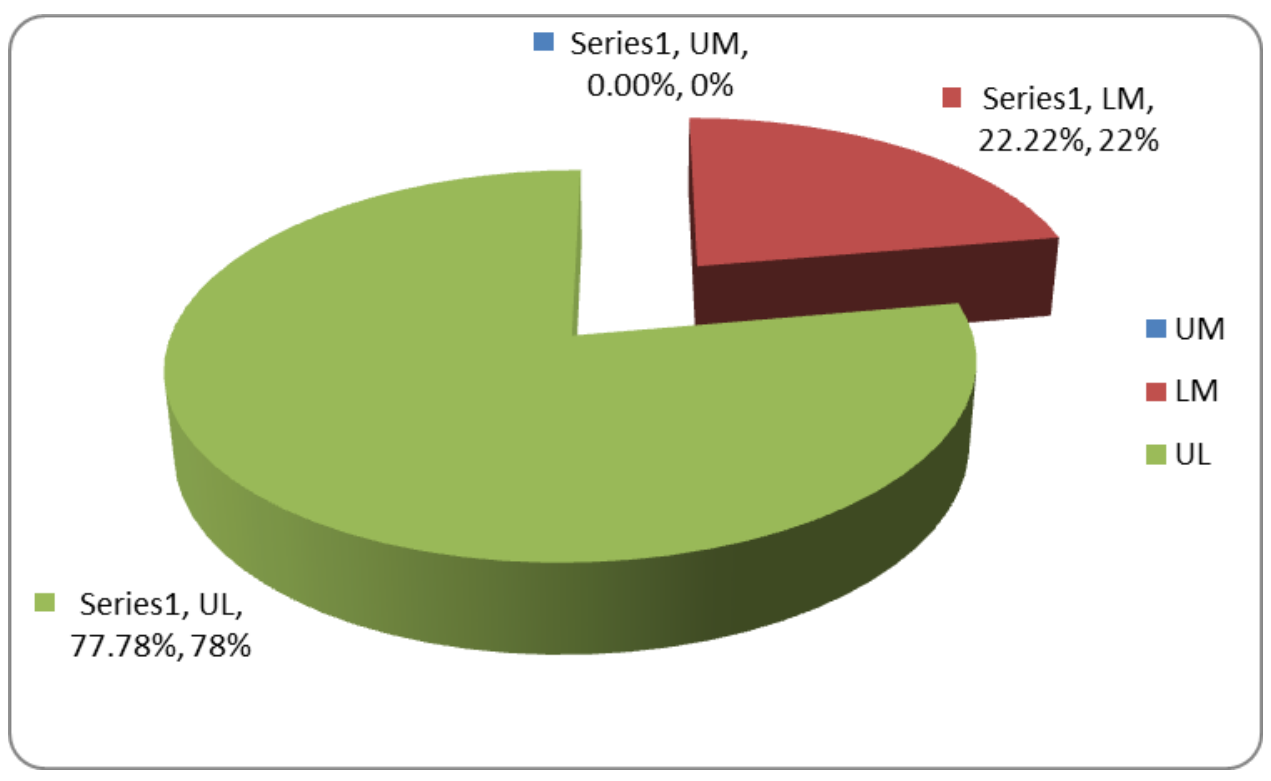


Food handlers play an important role in the dissemination and transmission of entero pathogenic microorganisms, including intestinal parasites. Asymptomatic individuals who work as food handlers may become potential sources of contamination and dissemination of several enteric pathogens. A number of outbreaks of viral and bacterial infections have already been shown to have been initiated by infected food handlers (Shinkawa et al., 2008, Stein-Zamir et al., 2008). Although such clear outbreaks have not been seen for intestinal parasitic infections, food handlers are still considered an important source of entero-parasitic infections. Their infection status continues to be monitored in many countries (Khurana et al., 2008, Abu-Madia et al., 2008, Beaty et al., 2009).

In this study, the majority [60 (51.72\%)] of food handlers were seen in the age group of 20-29 years. In a similar study by Mudey et al., (2009), it was found that 81 (50.62\%) food handlers were below 30 years of age, Deshpande et al., (2013) found 31 (45.33\%) of respondents were below 30 years of age, Udgiri et al., (2007) in their study conducted in Bijapur, Karnataka, it was observed that, $73.2 \%$ of food handlers were between 20-29 year age group, Mohan et al., (2001) found that $98(71.96 \%)$ of food handlers were below 30 years of age, in a study by Chitnis (1982) on food handlers, found that $73.87 \%$ food handlers were below 30 years of age.

In our study majority of food handlers were male $[105(90.52 \%)]$ and only $11(9.48 \%)$ were female with an overall male to female ratio of 9.55:1. Similar studies where male predominance is seen include Mohan et al., (2001) who found in their study, majority 206 $(96.26 \%)$ of food handlers were males and only $03.74 \%$ were females. Mudey et al., (2009) also found majority of food handlers were males $111(69.38 \%)$ and female 49
(30.62\%). But in contrast, in a study by Chitnis (1982) there was no any female food handler.

In our study most of the food handlers belonged to the (UL) upper lower socioeconomic class [67 (57.76\%)] followed by (LM) lower middle class [41 (35.34\%)] and (UM) upper middle class [8 $(6.90 \%)]$ but no food handlers were from upper class. On application of Chi square test, it was observed that there was a strong correlation between the socio-economic status of the foodhandler and the detection of enteric pathogen [p value $=0.00017]$. Similar study conducted by Takalkar et al., (2005) found that majority of food handlers were belonged to upper lower class [35 (42.2\%)] and only $5(6 \%)$ belonged to upper middle class.

In our present study it was found that $100 \%$ of the food handlers were practicing hand washing after toilet, $87(75 \%)$ were practicing hand washing and 29 (25\%) were not practicing hand washing after touching dirty materials or different body parts. Similar studies include, Mukhopadhyay et al., observed that $50.8 \%$ food handlers never washed their hands after touching body parts and handling money and $18.5 \%$ never washed hands in between handling raw and cooked food. However hand washing after going to toilet $(95.5 \%)$ and before preparing food (79.1\%) was reported to be quite high. Andargie et al., observed $89 \%$ of food handlers practiced hand washing and $11 \%$ of the food-handlers did not practice handwashing after visiting toilet.

In this present study, a total of 116 stool samples of food handlers were examined, out of which 18 stool samples were found to be positive for intestinal parasitic infestation and remaining 98 stool sample were found to be negative for parasitic infestation. The incidence of parasitic infestation in this study 
was found to be $15.52 \%$ i.e. in 18 out of 116 stool samples. Similar studies includes, Chitnis (1982) found $44.53 \%$ parasitic infestation, Khurana et al., (2001-2006) found $1.3 \%$ - 7\%, Mohan et al., (2001) found 14\%, Gashaw et al., (2003) found 29.1\%, Mohan U. et al., (2006) found 12.9\%, Udgiri R. S. et al., (2007) found 9.77\%, Ghosh et al., (2007) found $29.33 \%$, Kusolsuk T. et al., (20072008) found $10.3 \%$, Zaglool et al., (2009) found 23\%, Ifeadike et al., (2012) found $38.1 \%$ and Ramakrishnaiah et al., (2014) found $41 \%$ parasitic infestation. With reference to other studies mentioned above it is seen that our study is well within the range of parasitic infestation which varies from 1.3 $\%$ to $44.53 \%$.

We found that $18(15.52 \%)$ food handlers were suffering from parasitic infestation and among them, Entamoeba histolytica [7 (38.88\%)] was found to be the commonest followed by Ascaris lumbricoides [4 (22.22\%)], Giardia and hookworm [3 (16.67\%)] each and Trichuris trichuira [1 $(5.56 \%)]$. Studies showing similar parasitic infestations include, Mohan et al., (2001) found maximum with Entamoeba histolytica [12 (42.80\%)], followed by Ascaris lumbricoides [8 (28.60\%)] and Giardia lamblia [5 (17.80\%)]. Mohan et al., (2006) found highest with Entamoeba histolytica 12 (42.81\%), followed by $8(28.6 \%)$ of Ascaris lumbricoides and 5 (17.8\%) of Giardia lamblia infestation. In other studies where Ascaris lumbricoides was found to commonest includes Udgiri et al., (2007), Ghosh et al., who found $40.90 \%$ and $37.37 \%$ Ascaris lumbricoides respectively.

In our study no enteric bacterial pathogens could be detected. There were other similar studies where enteric bacterial pathogens like Salmonella or Shigella could not be detected. Sande et al., in their study could not isolate entero-pathogenic bacteria from stool culture.
No entero pathogenic bacteria were isolated in a study conducted by Kusolsuk et al., In a study conducted by Mohan et al., only one person $(0.47 \%)$ was found to have S. typhi in the stool sample. Khurana et al., did a study on food handlers from 2001-2006 and found that the rate of Shigella infection was $2 \%$ during the study period.

It is concluded, in this study, the incidence of intestinal parasites infection in food handlers was found to be $15.52 \%$. No enteropathogenic bacteria were isolated from the stool samples. Hand washing practice after touching dirty materials or different body parts was low (87\%) as compared to $100 \%$ hand washing practice after toilet. From our study as we found that the food handlers might be a source of transmission of pathogens to consumers, so we should give stress on maintaining good personal hygiene specially hand hygiene and hygienic food handling practices for preventing of transmission of pathogens from food handlers to consumers. From our study, we can concluded that the screening of food handlers and training for hand hygiene practices has to be give in every health care set up twice a year.

\section{Acknowledgement}

The authors would like to express their heartfelt gratitude to all the participants who have been enrolled in the study. We would also like to thank all the faculty members, pg trainees and the staff of department of Microbiology, Gauhati Medical College for their support and help in carrying out the study smoothly.

\section{References}

Abu-Madia MA, Behnkeb JM, Ismail A. Patterns of infection with intestinal parasites in Qatar among food handlers and housemaids from different 
geographical regions of origin. Acta Tropica. 2008;106:213-20.

Andargie G, Kassu A, Moges F, Tiruneh M, Huruy K. Prevalence of bacteria and intestinal parasites among food-handlers in Gondar town, northwest Ethiopia. J Health Popul Nutr 2008;26:451-5.

Andargie G, Kassu A, Moges F, Tiruneh M, Huruy K. Prevalence of bacteria and intestinal parasites among food-handlers in Gondar town, northwest Ethiopia. J Health Popul Nutr 2008;26:451-5.

Beatty ME, Shevick G, Shupe-Ricksecker K, Bannister E, Tulu A, Lancaster $\mathrm{H}$, et al. Large Salmonella enteritidis outbreak with prolonged transmission attributed to an infected food handler, Texas. Epidemiol Infect. 2009;137:417-27.

Chitnis UKB. An evaluation of heakth status of workers in eating establishments in pune cantonment (1982). Medical journal armed forces 1986; 2: 34-5.

Deshpande Jayant D, Phalke Deepak B. The Sanitary Condition of Food Establishments and Health Status and Personal Hygiene Among The Food Handlers in Rural Area of Western Maharastra, India. Asian Journal of Medical Science, Volume-4(2013).

Ghosh Arun, Mishra Prem Prakash, Sharma Ved Prakash. Prevalence of Parasitic Infestations amongst the Food Handlers in a City of North Eastern Region of India. NJIRM 2014; Vol. 5(2). MarchApril.

Ifeadike C. O., O. C. Ironkwe1, P. O. U. Adogu, C. C. Nnebue2, O. F. Emelumadu, S. A. Nwabueze, C. F. Ubajaka. Prevalence and pattern of bacteria and intestinal parasites among food handlers in the Federal Capital Territory of Nigeria. Nigerian Medical Journal | Vol. 53 | Issue 3 | July-September | 2012.

Khurana S, Aggarwal A, Malla N. Comparative analysis of intestinal parasitic infections in slum, rural and urban populations in and around union Territory, Chandigarh. J Commun Dis. 2005;37:239-43.

Khurana S, Taneja N, Thapar R, Sharma M and
Malla N "Intestinal bacterial and parasitic infection samong food handlers in a tertiary care hospital of North India" Tropical Gastroenterology 2008.29;4:207-209.

Kusolsuk T 1, Maipanich W 1, Nuamtanong S 1, Pubampen S 1, Sa-nguankiat S 1, Rojekittikhun W 1, Lekkla A 2, Tunyong W 3, Chettanadee S 3, Komalamisra C 1. Parasitic and Enteric Bacterial Infections among Food Handlers in Tourist-area Restaurants and Educational-institution Cafeterias, Sai-Yok District, Kanchanaburi Province, Thailand. The Journal of Tropical Medicine and Parasitology. Vol 34 (No. 2) December 2011.

Lillquist DR, McCabe ML, Church KH. A comparison of traditional hand washing training with active hand washing training in the food handler industry. J Environ Health. 2005;67:13-6.

Mackie and McCartney Practical Medical Microbiology fourteenth edition.p.108.

Maizun Mohd Zain and Nyi Nyi Naing. (2002). Socio-demographic characteristics of food handlers and their knowledge, attitude and practice towards food sanitation: A preliminary report SouthEast Asian Journal of tropical Med Public Health, Volume 33, Number 2, June, pp 410-417.

Mayta H, Talley A, Gilman RH, Jimenez J, Verastegui $M$, et al., Ruiz $M$ et al. Differentiating the Taenia solium and the Taenia saginata infections by simple haematoxylin-eosin staining and PCRrestriction enzyme analysis. $J$ Clin Microbiol 2000 Jan; 38(1):133-37.

Mead PS, Slutsker L and et al. (1999). Food related illness and death in the United States. Emerging Infectious Diseases, Volume 5, pp 607-625.

Mohan U, Mohan V, Raj K. A Study of Carrier State of S. typhi, Intestinal Parasites \& Personal Hygiene amongst Food Handlers in Amritsar City. Indian Journal of Community Medicine. 2006;31:60-1. 5 . 
Mohan V. et al. An evaluation of health status of food handlers of eating establishments in various educational and health institutions in Amritsar City. Indian Journal of Community Medicine.2001; 26(2): 80-84

Mohan V. et al. An evaluation of health status of food handlers of eating establishments in various educational and health institutions in Amritsar City. Indian Journal of Community Medicine.2001; 26(2): 80-84

Mudey A B, Kesharwani N, Abhay G, Mudey Ramchandra C. Goyal Ajay, K Dawale, Vasant V Wagh. Health Status and Personal Hygiene among Food Handlers Working at Food Establishment around a Rural Teaching Hospital in Wardha District of Maharashtra, India. Global Journal of Health Science Vol. 2, No. 2; October 2010.

Mukhopadhyay* P, Joardar G K, Kanad Bag, Samanta A, Sain S and Koley S "Identifying Key Risk Behaviors Regarding Personal Hygiene and Food Safety Practices of Food Handlers Working in Eating Establishments Located Within a Hospital Campus in Kolkata" Al Ameen J Med Sci (20 12 )5 (1 ):2 1 -2 8 .

Murat B, Azmi S, Ersun, Gokhan K. The evaluation of food hygiene, knowledge, attitudes, and practices of food handlers in food businesses in Turkey. Food Control. 2006; 17:317-322.

Parija S. C. textbook of Medical Parasitology, fourth edition

Park's textbook of preventive and social medicine, $22^{\text {nd }}$ edition

Ramakrishnaiah Y., Ketha Ravindra Reddy and Bhuvana Rachangan Screening of Intestinal Parasitic Infections Among
Food Handlers. Indian Journal of Medical Case Reports ISSN: 23193832(Online).

Robinson RD, Murphy EL, Wilks RJ, Neva FA, Terry SI, Hanchard B, et al. Gastrointestinal parasitic infection in healthy jamaican carriers of HTLV-I. J Trop Med Hyg. 1991;94:411-5.

Saeed HA, Hamid HH. Bacteriological and parasitological assessment of food handlers in the Odurman area of Sudan. J Microbiol Immunol Infect 2010;43:703.

Shinkawa N, Noda M, Yoshizumi S, Tokutake Y, Shiraishi T, Arita-Nishida T, et al. Molecular epidemiology of Noroviruses detected in food handler associated outbreaks of gastroenteritis in Japan. Intervirology. 2008;51:422-6.

Takalkar A A 1, Kumavat A P 2 Assessment of Personal Hygiene of Canteen Workers of Government Medical College and Hospital, Solapur. National Journal of Community Medicine Vol 2 Issue 3 Oct-Dec 2011.

Udgiri R, Masali KA. A study of health status and food hygiene practices among food handlers employed in some food establishment of Bijapur city. Indian Journal Of Medical Microbiology, vol. 32, issue 2, April 2007.

World Health Organization. Basic Laboratory Procedures in Clinical Laboratory. Second edition. WHO. Geneva 2003.

World Health Organization. Food safety and food borne illness. Geneva: WHO; 2007

Zaglool D. A., Khodari Y. A.1, Othman R. A. M., Farooq M. U.2. Prevalence of intestinal parasites and bacteria among food handlers in a tertiary care hospital. Nigerian Medical Journal | Vol. 52 | Issue 4 | October-December | 2011.

\section{How to cite this article:}

Rana Doley, Arunjyoti Sarmah and Dipa Barkataki. 2018. A Study of Enteric Bacterial and Parasitic Pathogens among the Food Handlers of Gauhati Medical College and Hospital. Int.J.Curr.Microbiol.App.Sci. 7(07): 4024-4034. doi: https://doi.org/10.20546/ijcmas.2018.707.468 